\title{
Mechanism of Glomerulotubular Balance. I. Effect of Aortic Constriction and Elevated Ureteropelvic Pressure on Glomerular Filtration Rate, Frac- tional Reabsorption, Transit Time, and Tubular Size in the Proximal Tubule of the Rat*
}

\author{
Floyd C. Rector, Jr., $\dagger$ Felix P. Brunner, $\ddagger$ and Donald W. Seldin with the \\ technical assistance of Martha Huddleston and Allen C. Nunn
}

(From the Department of Internal Medicine, The University of Texas Southwestern Medical School, Dallas, Texas)

It has long been recognized on the basis of clearance studies that changes in glomerular filtration rate (GFR) are associated with parallel changes in the tubular reabsorption of salt and water (1). More recently, micropuncture studies have defined both the site and the quantitative nature of this relationship. The observation that the tubular fluid to plasma ratio of inulin, $\left[(\mathrm{TF} / \mathrm{P})_{\mathrm{In}}\right]$ at the end of the proximal tubule remains constant in the face of wide variations in GFR (2-7) established this segment as the site of the interaction between GFR and tubular reabsorption. To be sure, sodium reabsorption in the proximal tubule may be influenced by other factors, especially those linked with changes in effective extracellular fluid volume $(6,8)$, independent of changes in GFR. The term glomerulotubular balance is reserved for those changes in reabsorption, attributable solely to alterations in GFR, that maintain a constancy of fractional reabsorption in the proximal tubule.

Theoretically, changes in GFR could influence tubular reabsorption by altering the rate of flow of tubular fluid, changing the geometry of the proximal tubule, or eliciting the secretion of a

\footnotetext{
* Submitted for publication August 25, 1965 ; accepted December 27, 1965.

This work was supported in part by a grant from the Dallas Heart Association and in part by training grant 5 TI HE 5469-04 from The National Institutes of Health, U. S. Public Health Service.

† Address requests for reprints to Dr. Floyd C. Rector, Jr., Dept. of Internal Medicine, The University of Texas Southwestern Medical School, 5323 Harry Hines Blvd., Dallas, Texas 75235.

$\ddagger$ Work performed as a trainee of the U. S. Public Health Service, grant 5 TI HE 5469-04.
}

hormone. In recent micropuncture studies $(6,7)$ in which glomerulotubular balance has been most rigorously demonstrated, GFR was acutely reduced by constricting either the renal artery or the aorta above the renal arteries. Reductions in GFR induced in this fashion, however, are associated with concomitant decreases in flow rate of tubular fluid and tubular size, as well as with activation of the renin-angiotensin system. In this experimental setting, therefore, it is difficult to identify which, if any, of these factors mediates glomerulotubular balance.

In the present studies the mechanism of glomerulotubular balance was examined under circumstances where these various influences could be dissociated. The effects of acute reductions in GFR, induced either by aortic constriction or elevation of ureteral pressure, on the relation between fractional reabsorption [estimated from (TF/ $P)_{\text {In }}$ ] and velocity flow (estimated from transit time) were examined in the proximal convoluted tubules of rats. Since aortic constriction was associated with visible decreases in tubular size, whereas increased ureteral pressure produced proximal dilatation, the role of tubular geometry could be easily ascertained.

Aortic constriction resulted in decreased GFR and decreased tubular size, but did not change either fractional reabsorption or transit time. In contrast, elevation of ureteral pressure decreased GFR but increased tubular size, transit time, and fractional reabsorption; in fact the absolute rate of reabsorption appeared to increase in direct proportion to tubular volume. These results exclude 
the rate of flow of tubular fluid as the factor mediating glomerulotubular balance and afford strong evidence that the balance between GFR and tubular reabsorption is mediated by tubular volume.

\section{Methods}

Experiments were performed in Sprague-Dawley rats, weighing 190 to $260 \mathrm{~g}$, that were anesthetized by intraperitoneal injection of sodium pentobarbital (40 to 60 $\mathrm{mg}$ per $\mathrm{kg}$ ), placed on a heated animal board, and prepared for micropuncture as previously described (9), with the exception that the kidney was exposed through a flank incision. During surgery the rats received 5 to $6 \mathrm{ml}$ of isotonic saline through a cannula in the jugular vein to compensate for extracellular fluid (ECF) losses at the surgical sites (10). Preliminary studies had shown that this amount of fluid replacement was adequate to restore GFR to normal without resulting in a saline diuresis, as judged from urinary to plasma inulin ratios ranging from 200 to 420 . These ratios indicate that urine flow is less than $0.5 \%$ of the GFR. Blood was collected in the midpoint of each period. The ureter was cannulated with polyethylene tubing and the urine collected in glass vials under oil. The urinary volume was determined by weighing.

The clearance of inulin $-{ }^{14} \mathrm{C}$ was measured by administering a priming dose of 1 to $1.5 \mu \mathrm{c}$ and a sustaining infusion of 5 to $10 \mu \mathrm{c}$ per hour in isotonic saline; the sustaining infusion was delivered at a rate of $0.02 \mathrm{ml}$ per minute with a calibrated Braun constant infusion pump. The rate of the sustaining infusion was decreased by $30 \%$ in the experimental periods of aortic constriction or increased ureteral pressure.

The estimation of inulin $-{ }^{14} \mathrm{C}$ clearances by the standard technique of measuring the urinary excretion of inulin was difficult in many of the experiments, particularly those with either aortic constriction or elevated ureteral pressure, because of errors due to the extremely low urine flows and comparatively large urinary dead spaces. To obviate these sources of error we used a constant infusion technique in which the GFR was estimated from the infusion rate of inulin divided by the steady state plasma concentration. This technique entails the assumption that the rate of inulin infusion is equal to the rate of urinary excretion. In preliminary experiments it was ascertained that a steady state plasma concentration was achieved after approximately 30 minutes of constant infusion. In addition, in five preliminary experiments it was found that the average GFR in three consecutive clearance periods measured with the constant infusion technique always checked within $8 \%$ of the average value obtained by measuring the urinary excretion of inulin.

During micropuncture experiments the GFR on the experimental side cannot be assumed to equal that of the control side. In such experiments, therefore, the measurement of GFR by the constant infusion technique requires that the contralateral kidney be removed. For this reason all animals used in the present studies were subjected to a right unilateral nephrectomy 1 to 3 weeks before the micropuncture experiment. In these rats the steady state concentration of inulin was very constant from period to period. The usual variation was less than $10 \%$; occasionally the variation would be as great as $15 \%$.

In all animals the transit time through the proximal convoluted tubule was repeatedly measured with the technique described by Steinhausen (11). Twenty-five to $50 \mu \mathrm{l}$ of a $10 \%$ solution of Lissamine green was injected through an indwelling polyethylene cannula in a jugular vein. The transit time was measured with stopwatches while the kidney surface was observed through the microscope. The first watch was started at the moment the kidney became green and stopped when the dye had cleared completely from all the proximal convoluted tubules. In most instances the dye cleared from all surface convolutions within 10 to 15 seconds after its first appearance in the kidney; usually the final clearance of dye occurred simultaneously in all surface nephrons. The second watch was used to measure the duration of the color wave in one loop. The duration of the color wave past a given point in the tubule was 3 to 6 seconds. This second time was subtracted from the first to give an approximation of the transit time from the glomerulus to the end of the proximal convolution.

To examine the relationship between $(T F / P)_{\text {In }}$ and transit time, tubules were punctured and fluid collected for the analysis of inulin; the time required for fluid to pass from glomerulus to collecting pipette was taken as the transit time. The end point was chosen as the collecting pipette rather than the end of the proximal tubule because it is the former and not the latter that determines the $(\mathrm{TF} / \mathrm{P})_{\text {In }}$ ratio. Each rat was given a priming dose of 10 to $20 \mu \mathrm{c}$ of inulin $-{ }^{14} \mathrm{C}$ and a sustaining infusion of 60 to $120 \mu \mathrm{c}$ per hour in isotonic saline at a constant rate of $0.02 \mathrm{ml}$ per minute. Forty to 60 minutes was allowed for equilibration before starting the collection of tubular fluid. Proximal convolutions were punctured with oil-filled micropipettes with ground tips ranging from 6 to $10 \mu$ in diameter. The tubules were injected either with a small oil droplet or a column of oil that filled several loops. The rate of collection was adjusted to prevent the oil drop from moving downstream or upstream. During the collections, which lasted approximately 3 to 10 minutes, 25 to $50 \mu$ l of a $10 \%$ solution of Lissamine green was injected rapidly into the jugular vein, and the interval between the first appearance of dye in the kidney and the moment dye first reached the collecting pipette was measured. This was repeated two to four times during each collection. After the sample was collected the tubule was injected with latex; subsequently, the puncture site was localized in the latex cast.

The concentration of inulin- $-{ }^{14} \mathrm{C}$ was measured by adding samples of infusion solution, plasma, urine, and tubular fluid to $10 \mathrm{ml}$ of Bray's solution and counting in a Packard Tricarb liquid scintillation counter. Approximately $0.03 \mu 1$ of tubular fluid and appropriate inulin ${ }^{-14} \mathrm{C}$ standards were pipetted with the same micropipette. The 
tubular fluid samples were always greater than three times background and were counted for more than 1,000 counts. All samples were counted before and after the addition of a known amount of inulin $-{ }^{14} \mathrm{C}$ standard to correct errors due to quenching. Plasma water was measured by refractometry and always found to be close to $94 \%$. Consequently, all $(\mathrm{TF} / \mathrm{P})_{\text {in }}$ were corrected for plasma water content of $94 \%$.

Tubular size was determined by photographing the surface of the kidney with high speed Ektachrome film in a Nikon model F camera mounted on a Leitz trinocular Ultrapak microscope. To increase the resolution of the tubular lumen the photographs were taken during transit time measurements while Lissamine green was in the tubular fluid. The same microscopic field was photographed repeatedly during each of the experimental maneuvers. The colored photograph was projected onto white paper and the magnified image traced. The tracings of several different convolutions in each field were cut out and weighed. The ratio of the experimental to control weights is equivalent to the ratio of the experimental to control radii, whereas the square of the ratio is equivalent to the ratio of the experimental to control tubular volumes.

1) Effects of lowering GFR by aortic constriction. In 13 rats undergoing saline diuresis measurements of GFR and transit time were obtained before and after aortic constriction; in four of the rats tubular size was also measured. After two to three control periods the aorta was constricted for two to three periods; the aortic constriction was then released and measurements obtained during one to two recovery periods.

In two additional rats undergoing saline diuresis repeat measurements of $(\mathrm{TF} / \mathrm{P})_{\text {In }}$ and transit time were made at the same tubular puncture site before and after aortic constriction. After the first collection the puncture site was labeled by depositing nigrosin in an adjacent area and drawing a map of the kidney surface (6).

Saline diuresis was induced by infusing a solution containing $125 \mathrm{mM} \mathrm{NaCl}$ and $25 \mathrm{mM} \mathrm{NaHCO}$ at a rate of $0.4 \mathrm{ml}$ per minute; fresh rat plasma was added to the infusion to deliver 0.01 to $0.02 \mathrm{ml}$ plasma per minute. Since urine flow was reduced by about $50 \%$ during the period of aortic constriction, the infusion rate was reduced to $0.2 \mathrm{ml}$ per minute.

The GFR was lowered by constricting the aorta above the renal artery. A ligature was passed around the aorta and threaded through a polyethylene tube. Tension placed on the ligature resulted in compression of the aorta against the end of the polyethylene tube. The degree of constriction was monitored by continuously measuring the blood pressure in a femoral artery with a Statham strain gauge connected to a Sanborn recorder. After control periods were obtained, the aorta was constricted to yield a blood pressure of 70 to $75 \mathrm{~mm} \mathrm{Hg}$ below the constriction. The animal was allowed to stabilize for approximately 30 to 40 minutes at the lower blood pressure before the experimental measurements and collections were taken.
2) Effects of lowering GFR by raising ureteropelvic pressure. In seven antidiuretic rats GFR, tubular size, and transit time were determined before and after increasing ureteral pressure. After three control periods ureteral pressure was elevated 25 to $40 \mathrm{~mm} \mathrm{Hg}$ by raising the fluid level in the ureteral catheter above the level of the rat. The rat was then permitted to equilibrate at this new level of ureteral pressure for approximately 40 minutes before the measurements were repeated.

The effect of increased ureteral pressure on the relation between $(T F / P)_{\text {In }}$ and transit time (time required for tubular fluid to pass from the glomerulus to the collecting pipette) was examined in two groups of rats. The first group consisted of nine normal rats, whereas the second group consisted of ten rats with increased ureteral pressure.

\section{Results}

Effects of lowering GFR by aortic constriction. Aortic constriction was performed in rats during saline diuresis because of the demonstration by Dirks, Cirksena, and Berliner (6) that reduction of GFR by 30 to $50 \%$ in dogs during saline diuresis did not alter the $(\mathrm{TF} / \mathrm{P})_{\text {In }}$ ratio. In the control periods before aortic constriction, the rats were excreting 3 to $10 \%$ of their glomerular filtrate. Constriction of the aorta sufficient to reduce the femoral blood pressure by about $50 \mathrm{~mm}$ $\mathrm{Hg}$ lowered GFR by 20 to $54 \%$ (Table I). Associated with the fall in GFR there was visible shrinkage in over-all kidney size and a measurable decrease in tubular volume; the per cent reduction in tubular volume was similar to the per cent decrease in GFR (Table I). Despite the reduction in GFR, transit time remained constant, with a mean of approximately 9 seconds. These transit times were much faster than those observed by Steinhausen (11) but agree very closely with those of Thurau and Deetjen (12). We have, however, observed transit times as long as those found by Steinhausen (e.g., approximately 20 to 30 seconds) in antidiuretic rats not given any saline to replace ECF losses due to surgery.

The reduction in GFR by 20 to $54 \%$ is comparable to that obtained by Dirks and associates (6) and Glabman, Aynedjian, and Bank (7); in both of these studies glomerulotubular balance, as reflected by a constant $(\mathrm{TF} / \mathrm{P})_{\text {In }}$, was observed. Nevertheless, to make certain that our transit times were obtained under the same conditions of glomerulotubular balance, the $(\mathrm{TF} / \mathrm{P})_{\text {In }}$ was measured in eight replicate studies (four in each of two 
TABLE I

Effect of aortic constriction on glomerular fultration rate and proximal transit time

\begin{tabular}{|c|c|c|c|c|c|c|}
\hline $\begin{array}{c}\text { Experi- } \\
\text { ment } \\
\text { no. }\end{array}$ & Period & $\begin{array}{c}\text { Blood } \\
\text { pressure }\end{array}$ & GF & & $\begin{array}{l}\text { Tubular } \\
\text { volume }\end{array}$ & $\underset{\text { time }}{\text { Transit }}$ \\
\hline 1 & $\begin{array}{l}\text { Control } \\
\text { Aortic const. } \\
\text { Recovery }\end{array}$ & $\begin{array}{r}m m H g \\
130 \\
80 \\
125\end{array}$ & $\begin{array}{c}\mathrm{ml} / \mathrm{min} / \mathrm{kg} \\
11.1 \\
7.7 \\
10.9\end{array}$ & $\begin{array}{c}\% \text { decrease } \\
31\end{array}$ & $\%$ decrease & $\begin{array}{c}\text { seconds } \\
7.5 \\
8.0 \\
8.0\end{array}$ \\
\hline 2 & $\begin{array}{l}\text { Control } \\
\text { Aortic const. }\end{array}$ & $\begin{array}{r}125 \\
75\end{array}$ & $\begin{array}{l}8.9 \\
5.6\end{array}$ & 37 & & $\begin{array}{l}8.5 \\
8.5\end{array}$ \\
\hline 3 & $\begin{array}{l}\text { Control } \\
\text { Aortic const. } \\
\text { Recovery }\end{array}$ & $\begin{array}{r}130 \\
80 \\
125\end{array}$ & $\begin{array}{r}12.2 \\
9.5 \\
11.8\end{array}$ & 22 & & $\begin{array}{l}8.5 \\
8.5 \\
8.0\end{array}$ \\
\hline 4 & $\begin{array}{l}\text { Control } \\
\text { Aortic const. } \\
\text { Recovery }\end{array}$ & $\begin{array}{r}120 \\
70 \\
120\end{array}$ & $\begin{array}{l}14.2 \\
10.3 \\
11.7\end{array}$ & 28 & & $\begin{array}{l}10.0 \\
11.5 \\
10.0\end{array}$ \\
\hline 5 & $\begin{array}{l}\text { Control } \\
\text { Aortic const. } \\
\text { Recovery }\end{array}$ & $\begin{array}{r}135 \\
70 \\
120\end{array}$ & $\begin{array}{r}11.5 \\
5.3 \\
8.0\end{array}$ & 54 & & $\begin{array}{l}9.5 \\
9.0 \\
9.0\end{array}$ \\
\hline 6 & $\begin{array}{l}\text { Control } \\
\text { Aortic const. } \\
\text { Recovery }\end{array}$ & $\begin{array}{r}110 \\
70 \\
110\end{array}$ & $\begin{array}{r}8.8 \\
6.6 \\
10.9\end{array}$ & 25 & & $\begin{array}{l}8.0 \\
8.0 \\
8.0\end{array}$ \\
\hline 7 & $\begin{array}{l}\text { Control } \\
\text { Aortic const. }\end{array}$ & $\begin{array}{r}115 \\
70\end{array}$ & $\begin{array}{r}13.3 \\
8.6\end{array}$ & 35 & & $\begin{array}{l}7.5 \\
7.0\end{array}$ \\
\hline 8 & $\begin{array}{l}\text { Control } \\
\text { Aortic const. } \\
\text { Recovery }\end{array}$ & $\begin{array}{r}125 \\
70 \\
100\end{array}$ & $\begin{array}{r}11.8 \\
7.2 \\
11.3\end{array}$ & 40 & & $\begin{array}{l}8.0 \\
8.0 \\
8.0\end{array}$ \\
\hline 9 & $\begin{array}{l}\text { Control } \\
\text { Aortic const. } \\
\text { Recovery }\end{array}$ & $\begin{array}{r}110 \\
65 \\
105\end{array}$ & $\begin{array}{r}10.9 \\
8.8 \\
11.1\end{array}$ & 20 & & $\begin{array}{l}8.0 \\
8.0 \\
8.0\end{array}$ \\
\hline 10 & $\begin{array}{l}\text { Control } \\
\text { Aortic const. }\end{array}$ & $\begin{array}{r}135 \\
70\end{array}$ & $\begin{array}{r}10.9 \\
7.8\end{array}$ & 28 & 35 & $\begin{array}{l}9.0 \\
9.0\end{array}$ \\
\hline 11 & $\begin{array}{l}\text { Control } \\
\text { Aortic const. }\end{array}$ & $\begin{array}{r}110 \\
70\end{array}$ & $\begin{array}{r}10.5 \\
7.9\end{array}$ & 25 & 30 & $\begin{array}{l}8.5 \\
8.0\end{array}$ \\
\hline 12 & $\begin{array}{l}\text { Control } \\
\text { Aortic const. }\end{array}$ & $\begin{array}{r}110 \\
70\end{array}$ & $\begin{array}{r}11.7 \\
7.3\end{array}$ & 38 & 30 & $\begin{array}{l}8.5 \\
8.5\end{array}$ \\
\hline 13 & $\begin{array}{l}\text { Control } \\
\text { Aortic const. }\end{array}$ & $\begin{array}{r}115 \\
75\end{array}$ & $\begin{array}{l}9.5 \\
6.5\end{array}$ & 32 & 20 & $\begin{array}{l}9.5 \\
9.5\end{array}$ \\
\hline
\end{tabular}

* GFR = glomerular filtration rate.

rats) before and after aortic constriction (Table II). During the control period the time required for the color wave to reach the collecting pipette ranged from 5.5 to 10.5 seconds; $(\mathrm{TF} / \mathrm{P})_{\text {In }}$ ranged from 1.53 to 2.12 (Table II). Aortic constriction decreased GFR by 37 and $52 \%$; however, there was no significant change in either transit time or $(\mathrm{TF} / \mathrm{P})_{\text {In }}$ ratio. It is therefore concluded that, when the GFR is lowered (up to $52 \%$ ) by aortic constriction in the range where glomerulotubular balance is preserved, the transit time remains constant.
Effects of increased ureteral pressure. Elevation of ureteral pressure by 25 to $40 \mathrm{~mm} \mathrm{Hg}$ uniformly lowered GFR by 20 to $37 \%$ of control values (Table III). This reduction in GFR was associated with two findings different from those observed when GFR was reduced to a similar extent by aortic constriction: the tubular volume increased by 23 to $56 \%$, and transit time increased by 67 to $245 \%$ (Table III).

To determine the state of glomerulotubular balance when GFR falls in association with prolongation of transit time and tubular dilatation, we com- 
TABLE II

Effect of aortic constriction on fractional reabsorption of filtrate and transit time in the proximal tubule

\begin{tabular}{|c|c|c|c|c|c|c|c|}
\hline \multirow{2}{*}{$\begin{array}{c}\text { Experi- } \\
\text { ment } \\
\text { no. }\end{array}$} & \multirow[b]{2}{*}{$\begin{array}{c}\text { Tubule } \\
\text { no. }\end{array}$} & \multicolumn{3}{|c|}{ Control* } & \multicolumn{3}{|c|}{ Aortic constriction $†$} \\
\hline & & GFR & $\underset{\text { time }}{\text { Transit }}$ & $(T F / P)_{I_{n}}$ & GFR & $\begin{array}{c}\text { Transit } \\
\text { time }\end{array}$ & $(T F / P)_{I n}$ \\
\hline & & $\mathrm{ml} / \mathrm{min} / \mathrm{kg}$ & seconds & & $\mathrm{ml} / \mathrm{min} / \mathrm{kg}$ & seconds & \\
\hline 1 & $\begin{array}{l}1 \\
2 \\
3 \\
4\end{array}$ & 11.5 & $\begin{array}{r}7.0 \\
8.5 \\
6.8 \\
10.5\end{array}$ & $\begin{array}{l}1.81 \\
1.97 \\
1.84 \\
2.09\end{array}$ & 7.2 & $\begin{array}{r}7.5 \\
8.5 \\
6.8 \\
11.0\end{array}$ & $\begin{array}{l}1.95 \\
1.87 \\
1.98 \\
2.23\end{array}$ \\
\hline 2 & $\begin{array}{l}1 \\
2 \\
3 \\
4\end{array}$ & 12.2 & $\begin{array}{l}5.5 \\
6.8 \\
7.2 \\
8.2\end{array}$ & $\begin{array}{l}1.53 \\
1.73 \\
2.12 \\
2.04\end{array}$ & 5.8 & $\begin{array}{l}5.7 \\
6.2 \\
8.0 \\
8.0\end{array}$ & $\begin{array}{l}1.38 \\
1.95 \\
2.35 \\
1.94\end{array}$ \\
\hline
\end{tabular}

* Average mean femoral arterial blood pressure between 110 and $125 \mathrm{~mm} \mathrm{Hg.} \quad(\mathrm{TF} / \mathrm{P})_{\mathrm{In}}=$ tubular fluid to plasma ratio of inulin.

$\dagger$ Mean femoral arterial blood pressure reduced to approximately 70 to $75 \mathrm{~mm} \mathrm{Hg}$.

pared the $(\mathrm{TF} / \mathrm{P})_{\text {In }}$ obtained in the group of animals with increased pelvic pressure with those obtained from normal rats. The results are charted in Tables IV and V and plotted in Figure 1.

Several difficulties arise in collecting proximal tubular fluid for $(\mathrm{TF} / \mathrm{P})$ In during periods of elevated ureteral pressure. Contamination of the sample by retrograde flow is especially likely because of high intratubular pressure. In a preliminary experiment it was found that, when the tubule was blocked distal to the pipette with a small drop of oil, proximal $(\mathrm{TF} / \mathrm{P})_{\text {In }}$ ratios of 10 to 100 were obtained. Much lower ratios were obtained when the tubule was blocked by filling several loops distal to the puncture site with oil.

TABLE III

Effect of increased ureteral pressure on glomerular filtration rate, proximal tubular size, and transit time

\begin{tabular}{|c|c|c|c|c|c|c|}
\hline \multirow[t]{2}{*}{$\begin{array}{c}\text { Experi- } \\
\text { ment } \\
\text { no. }\end{array}$} & \multirow{2}{*}{$\begin{array}{c}\begin{array}{c}\text { Ureteral } \\
\text { pressure }\end{array} \\
m m \mathrm{Hg}\end{array}$} & \multicolumn{2}{|c|}{ GFR } & \multirow{2}{*}{$\begin{array}{c}\begin{array}{c}\text { Tubular } \\
\text { volume }\end{array} \\
\begin{array}{c}\% \text { in- } \\
\text { crease }\end{array}\end{array}$} & \multicolumn{2}{|c|}{$\begin{array}{c}\text { Transit } \\
\text { time }\end{array}$} \\
\hline & & $\underset{\mathrm{kg}}{\mathrm{ml} / \min } /$ & $\begin{array}{l}\% \text { de- } \\
\text { crease }\end{array}$ & & seconds & $\begin{array}{l}\text { \% in- } \\
\text { crease }\end{array}$ \\
\hline 1 & $\begin{array}{r}0 \\
40\end{array}$ & $\begin{array}{l}8.1 \\
5.1\end{array}$ & 37 & 25 & $\begin{array}{r}6 \\
13\end{array}$ & 117 \\
\hline 2 & $\begin{array}{r}0 \\
25\end{array}$ & $\begin{array}{l}7.3 \\
4.7\end{array}$ & 36 & 23 & 31 & 245 \\
\hline 3 & $\begin{array}{r}0 \\
25\end{array}$ & $\begin{array}{l}9.3 \\
6.1\end{array}$ & 34 & 56 & $\begin{array}{l}12 \\
26\end{array}$ & 117 \\
\hline 4 & $\begin{array}{r}0 \\
30\end{array}$ & $\begin{array}{r}10.2 \\
7.6\end{array}$ & 26 & 39 & $\begin{array}{r}8 \\
19\end{array}$ & 137 \\
\hline 5 & $\begin{array}{r}0 \\
25\end{array}$ & $\begin{array}{r}10.0 \\
6.8\end{array}$ & 32 & 44 & $\begin{array}{r}8 \\
16\end{array}$ & 100 \\
\hline 6 & $\begin{array}{r}0 \\
25 \\
0\end{array}$ & $\begin{array}{l}5.9 \\
4.7 \\
5.4\end{array}$ & 20 & 24 & $\begin{array}{r}6 \\
10 \\
6\end{array}$ & 67 \\
\hline 7 & $\begin{array}{r}0 \\
40\end{array}$ & $\begin{array}{l}7.5 \\
5.5\end{array}$ & 27 & 23 & $\begin{array}{r}7 \\
12\end{array}$ & 71 \\
\hline
\end{tabular}

The large oil column necessary to prevent retrograde flow during increased ureteral pressure introduces the possibility that disturbances in flow dynamics will change transit time and $(\mathrm{TF} / \mathrm{P})_{\text {In }}$. This problem was investigated in the normal rats without increased ureteral pressure by measuring the transit time to a given site in the tubule before puncture, during puncture with the tubule blocked with a small oil drop, and during puncture with a large oil column. $(\mathrm{TF} / \mathrm{P})_{\text {In }}$ was also measured with the two different types of oil block.

In almost every puncture there was excellent agreement between the transit time before and during puncture. In two instances, however, transit time increased significantly during the puncture. In rat no. 3 (Table IV) the transit time increased from 5 seconds before puncture to 13.7 seconds during puncture; as will become apparent later, the $(\mathrm{TF} / \mathrm{P})_{\text {In }}$ of 2.78 is rather high for a location of $28 \%$ of the proximal tubule but is quite in line with the transit time of $13.7 \mathrm{sec}-$ onds. Consequently, this value was not included in the plot of $(\mathrm{TF} / \mathrm{P})_{\text {In }}$ against distance (Figure 1). Also, the fourth puncture in rat no. 4 showed an increase in transit time during the collection period. In cases where two consecutive samples were obtained from the same puncture site (indicated by asterisks in Table IV), first with a small oil drop in the tubular lumen and the second time with a large oil column, there was good agreement of both the transit times and the $(\mathrm{TF} / \mathrm{P})_{\text {In }}$ ratios. In observing the color wave it was always noted that the tubular fluid moved past the small 
TABLE IV

Relation between fractional reabsorption of filtrate and transit time in the proximal tubules of normal antidiuretic rats

\begin{tabular}{|c|c|c|c|c|c|}
\hline $\begin{array}{c}\text { Experi- } \\
\text { ment } \\
\text { no. }\end{array}$ & GFR & $\underset{\text { time }}{\text { Transit }}$ & $(T F / P)_{I_{n}}$ & $\begin{array}{l}\text { Filtrate } \\
\text { reab- } \\
\text { sorbed }\end{array}$ & Location \\
\hline & $\underset{\mathrm{kg}}{\mathrm{ml} / \min /}$ & seconds & & $\%$ & $\begin{array}{c}\text { \% prox- } \\
\text { imal } \\
\text { tubule }\end{array}$ \\
\hline \multirow[t]{5}{*}{1} & 9.8 & 8.0 & 2.01 & 50 & 48 \\
\hline & & 8.0 & $2.37 *$ & 58 & 48 \\
\hline & & 7.2 & $2.08 *$ & 52 & 48 \\
\hline & & 8.0 & 2.45 & 59 & 59 \\
\hline & & 6.0 & 1.80 & 44 & 44 \\
\hline \multirow[t]{4}{*}{2} & 6.9 & 6.7 & 1.92 & 48 & 52 \\
\hline & & 5.5 & $1.50^{*}$ & 33 & 42 \\
\hline & & 5.7 & $1.34 *$ & 25 & 42 \\
\hline & & 4.5 & 1.24 & 19 & 36 \\
\hline 3 & 9.1 & 13.7 & 2.78 & 64 & 28 \\
\hline \multirow[t]{6}{*}{4} & 8.0 & 5.3 & $1.70 *$ & 41 & 31 \\
\hline & & 4.3 & $1.61 *$ & 38 & 31 \\
\hline & & 6.2 & 1.84 & 46 & 46 \\
\hline & & 15.7 & 2.67 & 63 & $t$ \\
\hline & & 6.8 & $1.76^{*}$ & 43 & 46 \\
\hline & & 6.5 & $1.95 *$ & 49 & 46 \\
\hline \multirow[t]{4}{*}{$5 \ddagger$} & 9.0 & 8.3 & 1.92 & 48 & \\
\hline & & 7.0 & 2.02 & 50 & \\
\hline & & 10.0 & 1.87 & 46 & \\
\hline & & 7.0 & 1.95 & 49 & \\
\hline \multirow[t]{4}{*}{ · } & & 10.8 & 2.08 & 52 & \\
\hline & & 6.8 & 1.59 & 37 & \\
\hline & & 8.8 & 1.97 & 49 & \\
\hline & & 9.0 & 1.82 & 45 & \\
\hline \multirow[t]{8}{*}{6} & 7.9 & 6.7 & $1.99 *$ & 50 & 45 \\
\hline & & 5.8 & $1.83 *$ & 45 & 45 \\
\hline & & 9.0 & $2.26^{*}$ & 56 & $\dagger$ \\
\hline & & 7.5 & $2.01 *$ & 50 & $t$ \\
\hline & & 7.5 & $1.97 *$ & 49 & 43 \\
\hline & & 7.0 & $1.91 *$ & 48 & 43 \\
\hline & & 9.3 & $2.10^{*}$ & 52 & $\dagger$ \\
\hline & & 9.8 & $2.04 *$ & 51 & $t$ \\
\hline \multirow[t]{5}{*}{7} & 9.7 & 9.7 & 1.87 & 46 & $t$ \\
\hline & & 8.8 & 2.72 & 63 & 47 \\
\hline & & 6.8 & 1.42 & 30 & 50 \\
\hline & & 6.5 & 1.79 & 44 & $t$ \\
\hline & & 7.5 & 1.50 & 33 & $t$ \\
\hline \multirow[t]{3}{*}{$8 \S$} & 8.6 & & 1.60 & 37 & 48 \\
\hline & & & 1.47 & 32 & 39 \\
\hline & & & 1.17 & 15 & 9 \\
\hline \multirow[t]{4}{*}{$9 \S$} & 7.5 & & 1.90 & 47 & 57 \\
\hline & & & 2.21 & 55 & 63 \\
\hline & & & 2.09 & 52 & 52 \\
\hline & & & 2.40 & 58 & 61 \\
\hline
\end{tabular}

Repeat punctures in same tubule.

Inadequate localization of puncture site.

Kidney dropped during digestion procedure.

\$ Transit times not measured.

oil drop'but was stopped by the big oil column. These studies indicate, therefore, that the big oil column can effectively block the tubule without detectably altering flow and $(T F / P)_{\text {In. }}$. In normal rats the occasional case where flow dynamics are altered can be detected by the prolongation of the transit time (probably as a result of internal hydronephrosis) during the puncture.

In rats with elevated pelvic pressure, puncture may occasionally produce a very different disturbance. Tubular puncture, by decompressing the tubule, may cause the GFR to return to normal and the transit time to shorten. This undoubtedly occurred in a few instances where small leaks developed around the barrel of the micropipette. However, in most instances this probably did not occur. This is best illustrated by examining the relation between transit time to the collecting pipette and location of the puncture site, as shown in Figure 2. The points in the normal animals clustered in a very narrow range, with approximately 6 to 8 seconds required for the fluid to travel 40 to $50 \%$ of the length of the proximal tubule. With increased ureteral pressure, significantly longer times were required to reach any given point in the tubule. Five points, however, definitely fell in the normal range; in each of these instances the transit time was faster during puncture than before puncture, indicating that these tubules had been decompressed by the process of puncturing.

In the normal rats the GFR ranged from 6.9 to $9.8 \mathrm{ml}$ per minute per $\mathrm{kg}$ (Table IV). Twentyeight of the 44 samples had (TF/P) In below 2.0; 16 were between 2.0 and 3.0. When plotted as a function of distance along the proximal tubule (Figure 1, solid circles), it was seen that by the

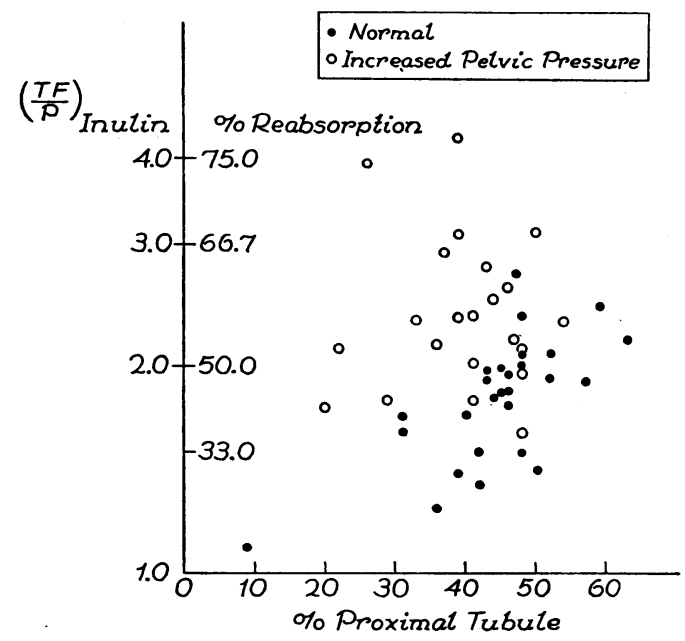

Fig. 1. EFFECT OF INCREASED URETEROPELVIC PRESSURE ON FRACTIONAL REABSORPTION IN THE PROXIMAL TUBULE. $(\mathrm{TF} / \mathrm{P})_{\text {Inu1 } n_{\mathrm{n}}}=$ tubular fluid to plasma ratio of inulin. 
TABLE V

Effect of increased ureteral pressure on the relation between fractional reabsorption of filtrate and transit time in the proximal tubule

\begin{tabular}{|c|c|c|c|c|c|c|}
\hline $\begin{array}{c}\text { Experi- } \\
\text { ment } \\
\text { no. }\end{array}$ & $\begin{array}{l}\text { Ureteral } \\
\text { pressure }\end{array}$ & GFR & $\underset{\text { time }}{\text { Transit }}$ & $(\mathrm{TF} / \mathrm{P})_{\mathrm{I}_{\mathrm{n}}}$ & $\begin{array}{l}\text { Filtrate re- } \\
\text { absorbed }\end{array}$ & Location \\
\hline & $m m \mathrm{Hg}$ & $\mathrm{ml} / \mathrm{min} / \mathrm{kg}$ & seconds & & $\%$ & $\begin{array}{c}\% \text { proximal } \\
\text { tubule }\end{array}$ \\
\hline 1 & 25 & 8.3 & $\begin{array}{r}11.0 \\
14.0 \\
6.0 \\
9.7\end{array}$ & $\begin{array}{l}3.10 \\
2.60 \\
1.65 \\
2.02\end{array}$ & $\begin{array}{l}68 \\
61 \\
39 \\
51\end{array}$ & $\begin{array}{l}39 \\
46 \\
30 \\
41\end{array}$ \\
\hline 2 & 35 & 5.3 & $\begin{array}{r}8.5 \\
11.3 \\
7.8 \\
13.5\end{array}$ & $\begin{array}{l}2.32 \\
2.12 \\
2.22 \\
2.43\end{array}$ & $\begin{array}{l}57 \\
53 \\
55 \\
59\end{array}$ & $\begin{array}{l}54 \\
22 \\
* \\
*\end{array}$ \\
\hline 3 & 22 & 7.1 & 9.2 & 2.79 & 64 & 43 \\
\hline 4 & 25 & 6.5 & 11.5 & 3.11 & 68 & 50 \\
\hline 5 & 40 & 6.0 & $\begin{array}{r}11.7 \\
11.2 \\
6.3 \\
12.5 \\
12.0\end{array}$ & $\begin{array}{l}2.19 \\
2.36 \\
1.95 \\
2.25 \\
2.09\end{array}$ & $\begin{array}{l}54 \\
58 \\
49 \\
55 \\
52\end{array}$ & $\begin{array}{l}47 \\
41 \\
48 \\
* \\
*\end{array}$ \\
\hline 6 & 25 & 5.8 & $\begin{array}{r}12.5 \\
10.8 \\
9.2 \\
6.5\end{array}$ & $\begin{array}{l}2.50 \\
2.06 \\
1.60 \\
1.78\end{array}$ & $\begin{array}{l}60 \\
51 \\
38 \\
44\end{array}$ & $\begin{array}{c}44 \\
* \\
48 \\
41\end{array}$ \\
\hline 7 & 40 & 5.1 & $\begin{array}{r}12.7 \\
4.5 \\
7.7 \\
4.5\end{array}$ & $\begin{array}{l}2.35 \\
1.74 \\
2.09 \\
1.49\end{array}$ & $\begin{array}{l}57 \\
42 \\
52 \\
33\end{array}$ & $\begin{array}{l}39 \\
20 \\
48 \\
*\end{array}$ \\
\hline 8 & 25 & 4.7 & $\begin{array}{r}13.3 \\
8.8\end{array}$ & $\begin{array}{l}2.77 \\
1.76\end{array}$ & $\begin{array}{l}64 \\
43\end{array}$ & $\begin{array}{c}* \\
29\end{array}$ \\
\hline $9 \dagger$ & 40 & 5.9 & $\begin{array}{r}9.3 \\
10.5 \\
5.0 \\
6.3 \\
5.8 \\
7.8 \\
6.8\end{array}$ & $\begin{array}{l}1.80 \\
4.28 \\
1.47 \\
1.51 \\
1.34 \\
1.77 \\
1.42\end{array}$ & $\begin{array}{l}44 \\
77 \\
32 \\
34 \\
25 \\
43 \\
30\end{array}$ & 39 \\
\hline 10 & 40 & 5.5 & $\begin{array}{r}9.0 \\
18.2 \\
11.5 \\
16.2\end{array}$ & $\begin{array}{l}2.33 \\
3.91 \\
2.82 \\
2.92\end{array}$ & $\begin{array}{l}57 \\
74 \\
65 \\
66\end{array}$ & $\begin{array}{l}33 \\
26 \\
* \\
37\end{array}$ \\
\hline
\end{tabular}

* Inadequate localization.

$\dagger$ Lissamine green injections were used to deliberately select puncture sites very early in the proximal tubule. Unfortunately, the kidney was dropped after only one tubule was localized.

time the fluid had traveled to the midpoint of the tubule $(50 \%)$ the $(\mathrm{TF} / \mathrm{P})_{\text {In }}$ had risen to approximately 2 , indicating the reabsorption of approximately $50 \%$ of the glomerular filtrate. This value is significantly lower than the fractional reabsorption observed by others and probably reflects the fact that the extensive loss of ECF during surgery was replaced in our animals.

In the rats with increased pelvic pressure the
GFR were significantly lower than in the normal animals, ranging from 4.7 to $8.3 \mathrm{ml}$ per minute per kg (Table V). Only 13 of 37 samples had $(\mathrm{TF} / \mathrm{P})_{\text {In }}$ ratios below 2.0 , whereas 19 were between 2.0 and 3.0, and 4 were above 3.0 (Table $\mathrm{V})$. The fact that elevated ureteral pressure increased fractional reabsorption is much more apparent when the $(\mathrm{TF} / \mathrm{P})_{\text {In }}$ ratios are plotted against distance (Figure 1, open circles). With 


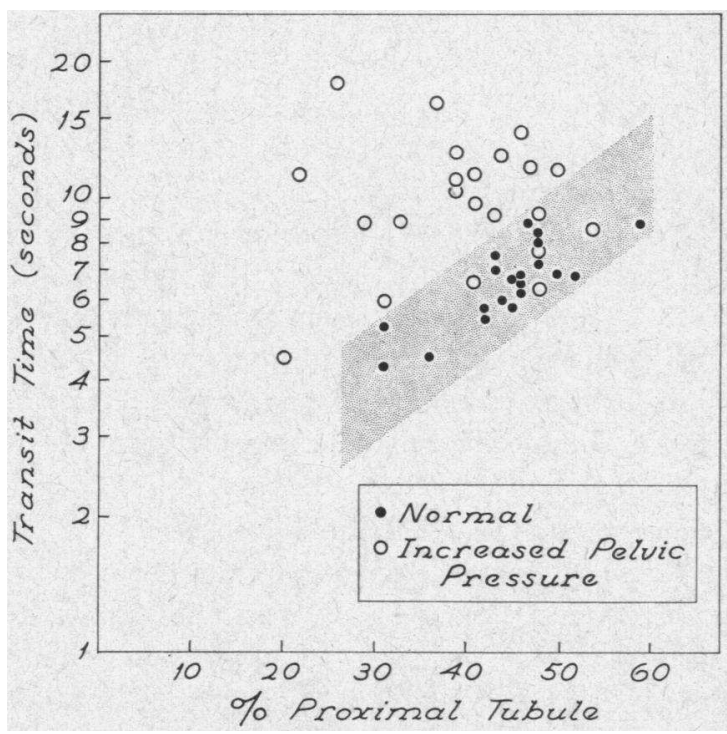

Fig. 2. EFFECT OF INCREASED URETEROPELVIC PRESSURE ON THE RELATION BETWEEN TRANSIT TIME AND DISTANCE IN THE PROXIMAL TUBULE. The transit time represents the time required for tubular fluid to pass from the glomerulus to a collecting pipette located at a given distance in the proximal tubule, expressed as per cent proximal tubule.

the exception of seven points all the values are significantly above the normal range. Five of these seven points also fell in the normal range of transit time versus distance (Figure 1) and had decreased transit times after tubular puncture. These $(\mathrm{TF} / \mathrm{P})_{\text {In }}$ ratios, therefore, are probably falsely low due to decompression of the tubule and restoration of normal flow and filtration by the process of tubular puncture.

\section{Discussion}

The present studies clearly demonstrate that reduction in GFR is not necessarily associated with a constant $(\mathrm{TF} / \mathrm{P})_{\text {In }}$ in the proximal tubule. The constancy of the $(\mathrm{TF} / \mathrm{P})_{\text {In }}$ depends entirely on the manner in which the GFR is reduced. When GFR was lowered by aortic constriction 30 to $50 \%$ below control values, $(\mathrm{TF} / \mathrm{P})_{\text {In }}$ remained constant (Table II). This is in accord with the observations of others in dogs (6) and rats (7) that large falls in GFR after aortic constriction are associated with a remarkably constant fractional reabsorption in the proximal tubule. However, when GFR was reduced to the same extent (20 to $40 \%$ ) by elevating ureteral pressure, $(\mathrm{TF} / \mathrm{P})_{\text {In }}$ rose
(Figure 1). It is obvious that the maintenance of glomerulotubular balance is not a necessary consequence of a fall in GFR, but is mediated by some additional factor correlated with aortic constriction and not with elevated ureteral pressure.

The constant $(\mathrm{TF} / \mathrm{P})_{\text {In }}$ during aortic constriction was associated with a reduction in tubular volume and a constant transit time (Table I). This is strong evidence that diminution in linear velocity is not responsible for glomerulotubular balance. The fact that glomerulotubular balance was maintained when reduction in GFR was associated with shrinkage of the proximal tubule (aortic constriction, Tables I and II) and disrupted when reduction in GFR was associated with dilatation of the proximal tubule (increased ureteral pressure, Tables III and V) suggests that tubular geometry is a critical factor mediating the precise adjustment of tubular reabsorption to GFR.

Gertz (13), on the basis of the finding that the intrinsic reabsorptive capacity of the tubular epithelium (measured in oil-blocked segments of proximal tubule with a stopped-flow microperfusion technique) varied proportionately to small spontaneous changes in tubular size had, in fact, suggested that in the intact nephron during free flow, alterations in tubular geometry might be responsible for the proportionate changes in reabsorptive rate and GFR. Such a mechanism, however, would require not only an exact proportionality between reabsorptive rate and tubular volume, but also between tubular volume and GFR. Gertz, however, presented no data bearing on this issue.

The relationships between reabsorptive rate, tubular volume, and GFR can be ascertained by analyzing the data from the present experiments according to a theoretical model developed by Gertz (13). According to this model, reabsorption in the proximal tubule can be described as a function of length (X) and transit time (T) by the following equations:

$$
\begin{gathered}
\text { fractional reabsorption }\left(1-\frac{1}{(\mathrm{TF} / \mathrm{P})_{\mathrm{In}}}\right) \\
=\frac{\mathrm{CX}}{\mathrm{Vo}} \\
\ln (\mathrm{TF} / \mathrm{P})_{\mathrm{In}}=\frac{\mathrm{CT}}{\pi \mathrm{r}^{2}}
\end{gathered}
$$


where $\mathrm{C}=$ reabsorptive rate constant per unit tubular length, $\mathrm{Vo}=\mathrm{GFR}$ per nephron, $\mathrm{r}=$ tubular radius, and $\pi \mathrm{r}^{2}=$ tubular volume per unit tubular length.

The principal assumption in this model is that the reabsorptive rate constant $\mathrm{C}$ is constant along the tubule so that each segment reabsorbs the same amount of fluid. This is in contrast to the model proposed by Kelman (14-16) in which the reabsorptive rate at any segment in the tubule is proportionate to the volume of fluid entering the segment; consequently, reabsorptive rate would decrease exponentially as a function of length. As pointed out by Gottschalk (17), the currently available micropuncture data that relate fractional reabsorption to distance along the proximal tubule are not sufficiently precise to permit a choice between these two models. Gertz (13), however, found that $\mathrm{C} / \pi \mathrm{r}^{2}$ measured by the shrinking-drop technique is the same in different portions of the proximal convolution; we have confirmed this finding (18). Since $\pi \mathrm{r}^{2}$ in the shrinking-drop technique is independent of tubular location, the constancy of the expression $\mathrm{C} / \pi \mathrm{r}^{2}$ suggests that the intrinsic reabsorptive properties of the proximal convoluted tubule are uniform along its length. Nevertheless, the absolute rate of reabsorption might progressively diminish because of either the accumulation of nonreabsorbable solutes or the effects of diminishing velocity flow. Accumulation of nonreabsorbable solutes, however, should exert a significant effect only after 70 to $80 \%$ of the filtrate is reabsorbed and should have no detectable effect on the kinetics of the reabsorption of the first 50 to $60 \%$ of filtrate (19). As will become apparent later in comparing the effects of aortic constriction and increased ureteral pressure, there is no apparent effect of velocity flow on reabsorptive rate.

Equations 1 and 2, therefore, can be used to examine the critical relationship between reabsorptive rate and tubular volume and tubular volume and GFR. When GFR (Vo) was reduced by aortic constriction, fractional reabsorption, or $(\mathrm{TF} / \mathrm{P})_{\text {In }}$, remained constant. This means that the right-hand side of Equation 1, CX/Vo, was constant. Since the site $(\mathrm{X})$ at which tubular fluid was sampled was the same before and after aortic constriction, C/Vo was constant. Similarly, the constancy of $(\mathrm{TF} / \mathrm{P})_{\text {In }}$ also means that the right-hand side of Equation 2, CT $/ \pi \mathrm{r}^{2}$, was constant. The demonstration (Tables I and II) that transit time ( $\mathrm{T}$ ) was not changed when GFR was reduced by aortic constriction means that $C / \pi r^{2}$ remained constant (Equation 2). The fact that $\mathrm{C} / \mathrm{Vo}$ and $\mathrm{C} / \pi \mathrm{r}^{2}$ both remained constant as Vo was reduced by aortic constriction indicates that Vo, C, and $\pi \mathrm{r}^{2}$ were changing proportionately. This suggests that the constancy of $(\mathrm{TF} / \mathrm{P})_{\text {In }}$ when GFR is reduced is mediated by a change in tubular volume that elicits a proportionate change in the reabsorptive rate.

To ascertain whether the reabsorptive rate (C) was proportionately increased when the proximal tubules were dilated, GFR was reduced by elevating ureteral pressure. Under these circumstances glomerulotubular balance was disrupted (Figure 1) and transit time prolonged. However, the relation between $(\mathrm{TF} / \mathrm{P})_{\mathrm{In}}$ and $\mathrm{T}$ was unaltered. As shown in Figure 3, the relation between $\log (\mathrm{TF} / \mathrm{P})_{\text {In }}$ and $\mathrm{T}$ was linear and had the same slope with or without ureteral pressure; a (TF/ $\mathrm{P})_{\text {In }}$ of 2 was attained in approximately $8.5 \mathrm{sec}-$ onds in both groups. Since the slope, which is $\mathrm{C} / \pi \mathrm{r}^{2}$, was not altered by increased ureteral pressure, it follows that the reabsorptive rate was elevated in proportion to the degree of tubular dilatation. In addition, the fact that $\mathrm{C} / \pi \mathrm{r}^{2}$ was the same in the two groups despite the marked differences in the velocity flow of fluid through the

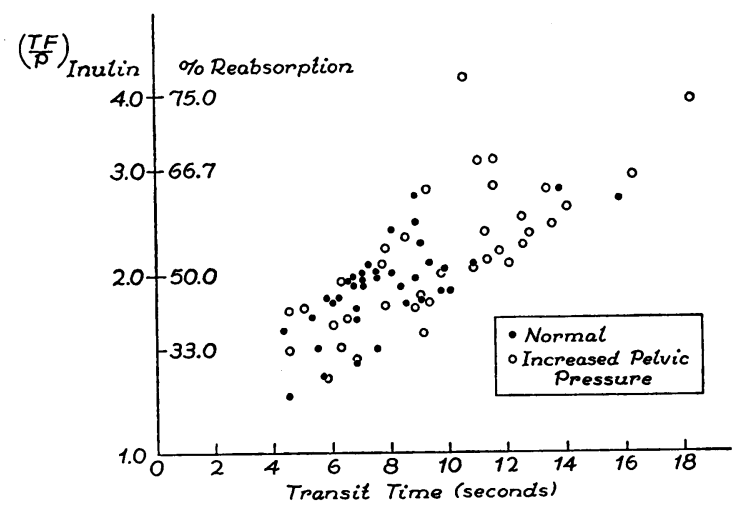

Fig. 3. EFFECT OF INCREASEd URETERopelvic PRESSURE ON THE RELATION BETWEEN FRACTIONAL REABSORPTION AND TRANSIT TIME. The transit time represents the time required for the tubular fluid to pass from the glomerulus to the site in the proximal tubule at which, the fluid was collected. 
tubule furnishes strong evidence that velocity has little or no effect on reabsorptive rate.

The results indicate that the value for $\mathrm{C} / \pi \mathrm{r}^{2}$ is not altered by either increased ureteral pressure or aortic constriction. It follows, therefore, that the reabsorptive rate and tubular volume vary proportionately during proximal dilatation (elevated ureteral pressure, glomerulotubular balance disrupted) as well as during proximal tubular shrinkage (aortic constriction, glomerulotubular balance preserved). It is, therefore, concluded that a reduction in GFR, if accompanied by tubular shrinkage, will be associated with a maintenance of glomerulotubular balance. If the reduction in GFR is associated with tubular dilatation, glomerulotubular balance will be disrupted. In either instance reabsorption is determined by tubular volume. Glomerulotubular balance is preserved during aortic constriction only because the proximal tubule shrinks.

At least three other mechanisms for maintaining glomerulotubular balance have been postulated and must be examined with respect to our data. Leyssac (20-23), extending the ideas of Rehberg (24) and Bojesen (25), has proposed that primary alterations in tubular reabsorption lead to secondary changes in GFR. According to this theory, decreased renal perfusion pressure releases angiotensin, which inhibits proximal tubular reabsorption (26); the decreased proximal reabsorption raises intratubular pressure transiently and thus lowers GFR. In the new steady state both GFR and tubular reabsorption would be reduced proportionately, but proximal intratubular pressure and volume would be maintained. In support of this theory Leyssac has found that partial clamping of the renal artery does not change either proximal intratubular pressure (22) or tubular volume, as estimated by histologic examination of snap-frozen kidneys (20).

The results of our studies are in conflict with Leyssac's proposal. Photographs of the surface of the kidney during aortic constriction revealed unequivocal decreases in tubular diameter ( $\mathrm{Ta}$ ble I). Furthermore, if proximal tubular volume were maintained constant, as suggested by Leyssac, the transit time would of necessity have to increase as GFR was decreased during aortic constriction. The fact that both transit time and $(\mathrm{TF} / \mathrm{P})_{\text {In }}$ remained constant (Table II) must mean that tubular volume diminished proportionately to the reduction in GFR. Finally, since Vander and Miller (27) have shown that both increased ureteral pressure and aortic constriction stimulate the release of renin, thereby increasing angiotensin activity, proximal reabsorption should be inhibited by either procedure. In our studies, however, not only did elevated ureteral pressure fail to suppress proximal reabsorption proportionate to the fall in GFR, but it resulted in an absolute increase in proximal reabsorption in direct proportion to the degree of tubular dilatation.

Berliner (28) has recently suggested that glomerulotubular balance is mediated by an internal feedback system in which changes in either the volume or composition of filtrate reaching the distal tubule are detected by some sensing device, possibly the macula densa; such stimuli either activate or suppress a local hormonal mechanism, which in turn produces appropriate readjustments of proximal reabsorption. The finding that despite comparable reductions in GFR, aortic constriction depressed, whereas elevated ureteral pressure enhanced, proximal reabsorption, is strong evidence against either the concentration or the absolute quantity of sodium in the fluid delivered to the distal tubule serving as the key variable in such a postulated internal feedback system. An alternative possibility, which is more difficult to assess, is that alterations in the volume of fluid delivered to the distal tubule cause either distension or collapse of this area of the nephron and thereby control the appropriate release of some hormonal agent. Thus, aortic constriction would cause collapse of the distal tubule with resultant feedback inhibition of proximal reabsorption, whereas increased ureteral pressure would distend the distal tubule, which would result in enhanced proximal reabsorption. The principal evidence against this possibility is that the distal volume changes associated with antidiuresis (collapse) and water diuresis (distension) should influence proximal reabsorption in a similar manner as aortic constriction and elevated pelvic pressure, respectively. ${ }^{1}$ This, however, does not occur. In

1 Although the dimensions of the distal tubule in antidiuresis and water diuresis have not been measured, Wirz (29) has shown that the distal intratubular pressure is higher in water diuresis than in antidiuresis (13 vs. $6 \mathrm{~mm} \mathrm{Hg}$ ). It is not unreasonable, therefore, to as- 
fact, the only available micropuncture data (30) comparing proximal reabsorption in water diuresis and antidiuresis suggest that water diuresis (and presumably distal distension) depresses rather than enhances proximal reabsorption. It seems unlikely, therefore, that glomerulotubular balance is mediated by an internal feedback system.

Finally, Kelman (14-16) has postulated that the proximal tubule is analogous to a catalytic flow reactor, so that the rate of reabsorption in any given segment of the proximal tubule is proportional to the volume delivered to it. Alteration in volume flow might influence tubular reabsorption in two ways: by variations in linear velocity and by variations in tubular radius. The possibility that the reabsorption of sodium in the fluid layer adjacent to the tubular epithelium generates radial concentration gradients of sodium, which are increased by slowed flow and dissipated by accelerated flow, has been discounted by Robinson (31) and by Friedlander and Walser (32), because the rate of sodium diffusion through a small layer of tubular fluid relative to the rate of sodium reabsorption is so great that radial concentration gradients could not exist. The fact that linear velocity did not change (i.e., constant transit time) under conditions where reabsorptive rate was decreased proportionately to GFR during aortic constriction, whereas fractional reabsorption was enhanced under conditions where linear velocity was decreased disproportionately to GFR (prolonged transit time) during elevation of ureteral pressure, excludes linear velocity as an important factor in maintaining glomerulotubular balance. Thus, if the element of linear velocity is excluded, $\mathrm{Kel}-$ man's model of glomerulotubular balance is similar to that proposed by Gertz (13), in that the only way in which alterations in volume flow can influence reabsorptive rate is through changes in tubular size.

Our studies, therefore, are not in accord with the models of glomerulotubular balance proposed by Leyssac (20), Berliner (28), and Kelman (14) and support the one suggested by Gertz (13). The results indicate that tubular size is a major determinant of reabsorptive rate and that glomerulotubular balance is the consequence of pro-

sume that the tubular dimensions are considerably larger in water diuresis. portionate changes in GFR, tubular volume, and reabsorptive rate.

The mechanism by which tubular radius or tubular volume is adjusted to changes in GFR is not entirely clear. In a distensible tubular system the tubular radius should be a function of the small difference between intratubular and peritubular pressures, rather than the actual intratubular pressure. However, it is not unreasonable to assume that, under conditions of varying GFR (increased ureteral pressure excluded), the pressure gradient across the tubular wall might vary proportionately to the absolute intratubular pressure. Although Leyssac (22) found that reducing GFR by partial clamping of the renal artery had no effect on intratubular pressure, Gertz (33) has recently shown that clamping the aorta above the renal artery lowered both GFR and intratubular pressure.

The proposed mechanism of glomerulotubular balance assigns the critical regulatory role to tubular geometry; proximal reabsorption is enhanced by tubular dilatation and diminished by tubular shrinkage. The diameter of the proximal tubule is in some manner regulated by intratubular pressure, which in turn is related to the volume of fluid emerging from the proximal tubule and the outflow resistance in Henle's loop. When GFR is elevated, the increased volume of fluid delivered to the loop of Henle causes a rise in proximal intratubular pressure and therefore tubular dilatation. In consequence, there is a proportionate increase in reabsorptive rate. The reduced volume of fluid leaving the proximal tubule when GFR is reduced causes a fall in intratubular pressure and tubular shrinkage; proximal reabsorption is thereby reduced proportionately. In either instance the changes in tubular size mitigate the effect of alterations in GFR and tend to preserve the volume of fluid delivered to the distal nephron.

\section{Summary}

The mechanism responsible for the maintenance of glomerulotubular balance was examined in rats whose filtration rates had been reduced to the same extent by either aortic constriction or elevated ureteral pressure.

During aortic constriction both the proximal tubular fluid to plasma inulin ratio and the transit time were constant. The constancy of the inulin 
ratio establishes that tubular reabsorption was diminishing in direct proportion to reductions in glomerular filtration rate (GFR), whereas the constancy of the transit time establishes that tubular volume was diminishing in direct proportion to reductions in GFR. This combination of findings means that reabsorptive rate diminished in proportion to the decrease in tubular volume.

After elevation of ureteral pressure, tubular size increased, transit time was prolonged, and glomerulotubular balance was disrupted. Nevertheless, despite the fall in glomerular filtration rate, proximal reabsorption did not diminish, but actually increased in direct proportion to the magnitude of tubular dilatation.

We concluded that proximal tubular reabsorption is a function of tubular volume. Glomerulotubular balance is maintained when tubular volume falls in proportion to GFR. Glomerulotubular balance is disrupted when tubular volume increases as GFR falls.

\section{Addendum}

Since submission of this manuscript, studies on glomerulotubular balance have been published by Gertz, Mangos, Braun, and Pagel (34). These investigators found that acutely lowering GFR in antidiuretic rats resulted in prolongation in transit time and elevation of $(\mathrm{TF} / \mathrm{P})_{\text {in }}$ ratios. It should be noted that in the experiments of Gertz and his associates the rats were not given adequate amounts of saline to replace surgical losses, so that the kidneys were functioning against the background of reduced effective ECF volume. We (18) have also observed that acutely lowering GFR in antidiuretic rats that are not given saline to replace surgical losses of extracellular fluid results in increased transit time and elevation of the calculated $(\mathrm{TF} / \mathrm{P})_{\text {In }}$ ratio; if, however, the rats are given sufficient saline to correct for surgical losses, but not enough to induce saline diuresis, transit time remains constant when GFR is reduced. Although the results obtained by Gertz and his colleagues and by us in nonsaline-repleted rats appear to be in disagreement with the results obtained in the present studies with rats undergoing saline diuresis, all of the studies are in complete agreement that $(\mathrm{TF} / \mathrm{P})_{\text {In }}$ is related to transit time $(T)$ by the expression, In $(T F / P)_{\text {In }}=\left(C T / \pi r^{2}\right)$, and that $\mathrm{C} / \pi \mathrm{r}^{2}$ is constant over a wide range of GFR.

Since $C / \pi r^{2}$ is constant in all of these studies, it can be concluded from Equations 1 and 2 in the text that tubular volume per unit length $\left(\pi r^{2}\right)$ is the primary factor governing intrinsic reabsorptive rate $(\mathrm{C})$ and that glomerulotubular balance will be maintained only when tubular volume changes proportionately to GFR. Thus, it appears that in rats given sufficient saline to replace surgical losses of extracellular fluid accruing during the micro- puncture procedure or in rats undergoing saline diuresis, acute reductions in GFR are associated with a proportionate fall in tubular volume and consequently maintain glomerulotubular balance. In constrast, in rats depleted of extracellular fluid by sequestration in the surgical site or in rats with acute hydronephrosis, reductions in GFR are not associated with proportionate decreases in tubular volume; therefore, glomerulotubular balance is disrupted.

These results suggest that alterations in extracellular fluid volume have two distinct consequences. First, as shown by Dirks, Cirksena, and Berliner (6), expansion of ECF volume suppresses fractional reabsorption in the proximal tubule while GFR remains constant. It is reasonable to assume that contraction of ECF volume increases proximal reabsorption independent of GFR. Second, when ECF volume is normal or expanded, acute changes in GFR are associated with maintenance of glomerulotubular balance; however, when ECF volume is diminished, the response to acute reductions in GFR is altered so that glomerulotubular balance does not occur.

\section{References}

1. Wesson, L. G., Jr. Glomerular and tubular factors in the renal excretion of sodium chloride. Medicine (Baltimore) 1957, 36, 281.

2. Walker, A. M., P. A. Bott, J. Oliver, and M. C. MacDowell. The collection and analysis of fluid from single nephrons of the mammalian kidney. Amer. J. Physiol. 1941, 134, 580.

3. Lassiter, W. E., M. Mylle, and C. W. Gottschalk. Net transtubular movement of water and urea in saline diuresis. Amer. J. Physiol. 1964, 206, 669.

4. Giebisch, G., R. M. Klose, and E. E. Windhager. Micropuncture study of hypertonic sodium chloride loading in the rat. Amer. J. Physiol. 1964, 206, 687.

5. Giebisch, G., and E. E. Windhager. Renal tubular transfer of sodium, chloride and potassium. Amer. J. Med. 1964, 36, 643.

6. Dirks, J. H., W. J. Cirksena, and R. W. Berliner. The effect of saline infusion on sodium reabsorption by the proximal tubule of the dog. J. clin. Invest. 1965, 44, 1160.

7. Glabman, S., H. S. Aynedjian, and N. Bank. Micropuncture study of the effect of acute reductions in glomerular filtration rate on sodium and water reabsorption by the proximal tubules of the rat. J. clin. Invest. 1965, 44, 1410.

8. Rector, F. C., Jr., G. Van Giesen, F. Kiil, and D. W. Seldin. Influence of expansion of extracellular volume on tubular reabsorption of sodium independent of changes in glomerular filtration rate and aldosterone activity. J. clin. Invest. 1964, 43, 341.

9. Rector, F. C., Jr., and J. R. Clapp. Evidence for active chloride reabsorption in the distal renal tubule of the rat. J. clin. Invest. 1962, 41, 101.

10. Shires, T., J. Williams, and F. Brown. Acute change in extracellular fluids associated with major surgical procedures. Ann. Surg. 1961, 154, 803. 
11. Steinhausen, M. Eine Methode zur Differenzierung proximaler und distaler Tubuli der Nierenrinde von Ratten in vivo und ihre Anwendung zur Bestimmung tubulärer Strömungsgeschwindigkeiten. Pflügers Arch. ges. Physiol. 1963, 277, 23.

12. Thurau, K., and P. Deetjen. Kinematographische Untersuchungen am Warmblütlernephron. Nachr. Akad. Wiss. Göttingen II. 1961, 2, 27.

13. Gertz, K. H. Transtubuläre Natriumchloridflüsse und Permeabilität für Nichtelektrolyte im proximalen und distalen Konvolut der Rattenniere. Pflügers Arch. ges. Physiol. 1963, 276, 336.

14. Kelman, R. B. A theoretical note on exponential flow in the proximal part of the mammalian nephron. Bull. math. Biophys. 1962, 24, 303.

15. Kelman, R. B. Mathematical analysis of sodium reabsorption in proximal part of nephron in presence of nonreabsorbed solute. J. theor. Biol. 1965, 8, 22.

16. Kelman, R. B. Mathematical analysis of sodium reabsorption in the proximal part of the nephron in Proceedings of the 2nd Annual Symposium on Biomathematics and Computer Sciences in the Life Sciences, C. Mountain, Ed. Springfield, Ill., Charles C Thomas, in press.

17. Gottschalk, C. W. Renal tubular function: lessons from micropuncture. Harvey Lect. 1963, 58, 99.

18. Brunner, F. P., F. C. Rector, Jr., and D. W. Seldin. Mechanism of glomerulotubular balance. II. Regulation of proximal tubular reabsorption by tubular volume, as studied by stopped-flow microperfusion. J. clin. Invest. 1966, 45, 603.

19. Pitts, R. F. Physiology of the Kidney and Body Fluids. Chicago, Year Book, 1963, pp. 100-101.

20. Leyssac, P. P. Dependence of glomerular filtration rate on proximal tubular reabsorption of salt. Acta physiol. scand. 1963, 58, 236.

21. Leyssac, P. P. The in vivo effect of angiotensin on the proximal tubular reabsorption of salt in rat kidneys. Acta physiol. scand. 1964, 62, 436.
22. Leyssac, P. P. The effect of partial clamping of the renal artery on pressures in the proximal and distal tubules and peritubular capillaries in the rat kidney. Acta physiol. scand. 1964, 62, 449.

23. Leyssac, P. P. Some characteristics of the proximal tubular wall related to reabsorption during luminal occlusion following interruption of glomerular filtration. Acta physiol. scand. 1965, 63, 36.

24. Rehberg, P. B. Uber die Bestimmung der Menge des Glomerulusfiltrats mittels Kreatinin, nebst einigen Bemerkungen über die Theorien der Harnbereitungen. Zentrbl. ges. inn. Med. U. Grenzgeb. 1929, 50, 367.

25. Bojesen, E. The renal mechanism of "dilution diuresis" and salt excretion in dogs. Acta physiol. scand. 1954, 32, 129.

26. Gertz, K. H. Direct measurement of the transtubular flux of electrolytes and nonelectrolytes in the intact rat kidney in Proceedings of the 22nd International Congress on Physiological Sciences, Leiden, Excerpta Medica, 1962, p. 370.

27. Vander, A. J., and R. Miller. Control of renin secretion in the anesthetized dog. Amer. J. Physiol. 1964, 207, 537.

28. Berliner, R. W. Personal communication.

29. Wirz, H. Die Druckverhältnisse in der normalen Niere. Schweiz. med. Wschr. 1956, 86, 377.

30. Clapp, J. R., J. F. Watson, and R. W. Berliner. Osmolality, bicarbonate concentration, and water reabsorption in proximal tubule of the dog nephron. Amer. J. Physiol. 1963, 205, 273.

31. Robinson, J. R. Some Reflections on Renal Function. Springfield, Ill., Charles C Thomas, 1954, pp. 83-87.

32. Friedlander, S. K., and M. Walser. Some aspects of flow and diffusion in the proximal tubule of the kidney. J. theor. Biol. 1965, 8, 87.

33. Gertz, K. H. Personal communication.

34. Gertz, K. H., J. A. Mangos, G. Braun, and H. D. Pagel. On the glomerular tubular balance in the rat kidney. Pflügers Arch. ges. Physiol. 1965, 285, 360 . 